\title{
ASSISTÊNCIA SOCIAL E UNIVERSIDADE: UMA INTERFACE NECESSÁRIA
}

\author{
Andréa Elizabeth Abreu Machadoํㅡㄹ Daniela Vale de Oliveira², \\ Eliza Ribeiro Chaves 3 , Mathaeus Levy Alves Pontelo 4
}

\begin{abstract}
Resumo: $\mathrm{O}$ intuito deste artigo é fomentar o debate sobre o acompanhamento às famílias de baixa renda e/ou expostas a situações de risco e vulnerabilidade social para além dos espaços formais e institucionalizados da Assistência Social. Para tal apresentaremos a recente experiência em articulação com o projeto de extensão intitulado "Valorização e Capacitação Técnica de Jovens e Mulheres para o Turismo", do Departamento de Turismo da Universidade Federal de Ouro Preto (DETURUFOP) e desenvolvido com e para a comunidade ouropretana em parceria com diferentes profissionais da política de Assistência Social. Como será abordado ao longo deste estudo, buscou dentre outros objetivos, o desenvolvimento do papel de cidadão enquanto pertencente ao espaço político, social e cultural. A diante, caberá análise dos impactos na vida dos participantes, além dos desafios e potencialidades da articulação entre os diferentes sujeitos envolvidos neste processo, bem como a construção de um perfil dos usuários envolvidos diretamente no projeto em tela.
\end{abstract}

Palavras-chave: Extensão universitária; Assistência Social; Famílias.

1 Graduada em Serviço Social pela UFJF (Universidade Federal de Juiz de Fora), especialista em Gestão de Políticas Públicas pela UFOP (Universidade Federal de Ouro Preto), Assistente Social na Prefeitura Municipal de Ouro Preto-MG.

2 Graduada em Psicologia pela UFSJ (Universidade Federal de São João Del Rey), especialista em Psicodrama Psicoterapêutico pelo Instituto Mineiro de Psicodrama Jacob Levy Moreno, Psicóloga na Prefeitura Municipal de Ouro Preto-MG. Mestranda em Educação da UFOP (Universidade Federal de Ouro Preto).

3 Estudante de Serviço Social na UFOP (Universidade Federal de Ouro Preto), estagiária na Prefeitura Municipal de Ouro Preto - MG.

4 Graduado em Turismo pela UFOP (Universidade Federal de Ouro Preto), Superintendente de Desenvolvimento Social na Prefeitura Municipal de Ouro Preto - MG. 


\section{ASISTENCIA SOCIAL Y UNIVERSIDAD: UNA INTERFAZ NECESARIA}

Resumen: La intención de este artículo es fomentar el debate sobre el acompañamiento a las familias de bajos ingresos y / o expuestas a situaciones de riesgo y vulnerabilidad social más allá de los espacios formales e institucionalizados de la Asistencia Social. Para ello presentaremos la reciente experiencia en articulación con el proyecto de extensión titulado "Valorización y Capacitación Técnica de Jóvenes y Mujeres para el Turismo", del Departamento de Turismo de la Universidade Federal de Ouro Preto (DETUR-UFOP) y desarrollado con y para la comunidad ouropretana adjunto a diferentes profesionales de la política de Asisténcia Social. Como se abordará a lo largo de este estudio, buscó entre otros objetivos, el desarrollo del papel de ciudadano como perteneciente al espacio político, social y cultural. A la vez, cabría analizar los impactos en la vida de los participantes, además de los desafíos y potencialidades de la articulación entre los diferentes actores involucrados en este proceso, así como la construcción de un perfil de los usuarios involucrados directamente en el proyecto analisado.

Palabras clave: Extensión universitária; Asistencia social; Familias.

\section{SOCIAL ASSISTANCE AND UNIVERSITY: A NECESSARY INTERFACE}

Abstract: The purpose of this article is to promote the debate about the follow-up to low salary families and /or exposed to situations of risk and social vulnerability beyond the formal and institutionalized spaces of Social Assistance. For this, we will present the recent experience in articulation with the extension project titled "Valorization and Technical Training of Youth and Women for Tourism", of the Department of Tourism of the Federal University of Ouro Preto (DETURUFOP) and developed with and for the community ouropretana in partnership with different professionals of the Social Assistance departament. As it will be approached throughout this study, it sought among other objectives, the development of the role of citizen while belonging to the political, social and cultural space. Ahead will be the analysis of the impacts on participants' lives, as well as the challenges and potentialities of articulation between the different subjects involved in this process, as well as the construction of a profile of the users directly involved in the screen project.

Key words: University extension; Social assistance; Families.

\section{INTRODUÇãO}

Este artigo visa apresentar as relações sociais estabelecidas entre diferentes sujeitos no município de Ouro Preto/MG cuja mediação é realizada pelo 
projeto de extensão universitária "Valorização e Capacitação Técnica de Jovens e Mulheres para o Turismo". Esta iniciativa se desenvolveu ao longo do ano de 2017 pelo Departamento de Turismo da Universidade Federal de Ouro Preto e a Prefeitura Municipal de Ouro Preto, mais especificamente pela Secretaria de Desenvolvimento Social, Habitação e Cidadania (SMDSHC).

A Cidade Histórica de Ouro Preto situa-se na região central de Minas Gerais e localiza-se em uma das principais áreas do ciclo do ouro, sendo famosa também por sua arquitetura colonial. Fundada em 1711, foi o primeiro sítio brasileiro a ser considerado Patrimônio Mundial da UNESCO, título recebido no ano de 1980. Já havia sido considerada Patrimônio Estadual em 1933 e Monumento Nacional em 1938.

Cidade com grande potencial turístico, Ouro Preto detêm grande parcela de sua população economicamente vinculada às atividades mineradoras, atraindo muitos trabalhadores de diversas partes do país. Também marca a história e o desenvolvimento de Ouro Preto a presença da Universidade Federal de Ouro Preto inaugurada em agosto de 1969 com a junção das centenárias e tradicionais: Escola de Farmácia e Escola de Minas. Cidade universitária, segundo dados do IBGE, Ouro Preto possui uma população de 70.281 habitantes, conforme dados do último senso realizado em 2010.

Repleta de particularidades, Ouro Preto do século XXI apresenta também características próprias da sua época, como crescente desemprego e vínculos informais e/ou precarizados de trabalho, crise econômica, avanço da violência urbana e doméstica. Embora a cidade abrigue o maior conjunto arquitetônico do barroco brasileiro e seja expoente no cenário turístico internacional, observa-se que os sujeitos, em sua maioria, sentem-se alijados dos processos produtivos existentes na cidade. Soma-se ainda um movimento de exclusão por parte de parcela significativa dos ouropretanos, nos quais não desenvolveram o sentimento de pertença dentro do seu território, assistindo inertes e alheios aos mais importantes eventos econômicos, políticos, artísticos, sociais e culturais realizados em sua cidade. Tal realidade impõe ao Estado intervenções de enfrentamento cada vez mais sistêmicas e intersetoriais às expressões da Questão Social.

Sobre sua origem IAMAMOTO (1998) explica:

[...] a Questão Social é apreendida como um conjunto das expressões das desigualdades da sociedade capitalista madura, que tem uma raiz comum: a produção social é cada vez 
mais coletiva, o trabalho torna-se mais amplamente social, enquanto a apropriação dos seus frutos mantém-se privada, monopolizada por uma parte da sociedade (p.27).

Acresce-se a esta análise, o reconhecimento da função social da extensão universitária e a indissociabilidade com o ensino e a pesquisa. Elemento estruturante da universidade pública, a extensão pode se constituir como um espaço de trabalho educativo, de formação humana e profissional dos acadêmicos e de diálogo com a comunidade, quando se volta efetivamente para essas demandas. (FRIZZO, MARIN \& SCHELLIN, 2016). Foi contemplando esta lógica que a Secretaria de Desenvolvimento Social, Habitação e Cidadania de Ouro Preto, por intermédio dos profissionais do Centro de Referência de Assistência Social Alto da Cruz firmou parceria com o Departamento de Turismo - DETUR/UFOP.

Através desta ação, definiu-se como público-alvo prioritariamente as famílias atendidas pelo PAIF - Serviço de Proteção e Atendimento Integral às Famílias, desenvolvido por este CRAS, devido demanda identificada pela equipe técnica interdisciplinar nele atuante. Os critérios de seleção foram a maior recorrência na solicitação de serviços e benefícios ofertados neste Centro de Referência e o interesse em participar, alcançando assim um público frequente de 20 a 25 adultos, entre homens e mulheres.

Vale frisar, conforme Tipificação Nacional de Serviços Socioassistenciais, aprovada por meio da Resolução no 109 , de 11 de novembro de 2009, do Conselho Nacional de Assistência Social - CNAS, a prioridade deste público no acompanhamento profissional, devido as situações de risco e vulnerabilidade sociais identificados.

Conceitos recorrentes em diversas áreas de conhecimento e políticas públicas, o risco social é definido como a probabilidade ou a iminência de um evento ou conjunto de eventos ocorrer. A vulnerabilidade, por seu turno, é entendida de acordo com o Ministério de Desenvolvimento Social e Agrário - MDSA, como "uma conjugação de fatores envolvendo, via de regra, características do território, fragilidade ou carência das famílias, grupos ou indivíduos e deficiências da oferta e do acesso a políticas públicas" (2016, p. 20). Risco, vulnerabilidade e território estão intimamente inter-relacionados e propiciam elementos para análise e respostas em termos de oferta de programas, projetos, serviços e benefícios, no âmbito da Proteção Social Básica. 
Como objetivos do projeto de extensão buscou-se preparar jovens e adultos para o mercado de trabalho formal; desenvolver o sentimento de pertença no grupo e possibilitar o amplo conhecimento da riqueza física e cultural local. Ademais, logrou-se de importante momento de reflexão sobre aspectos da vivência comunitária e a interação familiar e de entretenimento ao grupo. Infere-se ainda, que indiretamente foi visado o fortalecimento da política pública traçada para o PAIF, qual seja, a de promover às famílias o seu acesso e usufruto de direitos e contribuir na melhoria de sua qualidade de vida.

A inserção da noção de pertencimento neste texto está estreitamente relacionada às vivências grupais desenvolvidas pela equipe técnica do CRAS Alto da Cruz e às manifestações brotadas das mesmas. Este conceito conduz, inevitavelmente, a um processo sistêmico, no qual muitas histórias pulsam. Metaforicamente, pode-se dizer de gritos que não encontram eco nas fortes muralhas do rico patrimônio Barroco desta "província". Todavia, basta um gesto sensível e atento para florescer as pessoas na sua singularidade e dar sentido a um conjunto de comportamentos até então percebidos como desconexos do contexto no qual ocorrem.

A possibilidade da escuta, individual e/ou coletiva, foi o movimento precipitador para a melhor compreensão do que entende-se aqui como uma dificuldade apresentada pelo ouropretano - seja aquele neste local nascido ou até mesmo o que firmou suas raízes afetivas ou patrimoniais nesse território - de desenvolver um sentimento de identidade em suas terras.

LESTINGE (2004) ajuda a compreender melhor este fenômeno.

A priori esse conceito - pertencimento - pode nos remeter a, pelo menos, duas possibilidades: uma vinculada ao sentimento por um espaço territorial, ligada, portanto, a uma realidade política, étnica, social e econômica, também conhecida como enraizamento; e outra, compreendida a partir do sentimento de inserção do sujeito, sentir-se integrado a um todo maior, numa dimensão não apenas concreta, mas também abstrata e subjetiva. (LESTINGE, 2004, p. 40)

Com base nessa dupla interpretação do termo pode-se reconstruir o universo histórico que aqui interessa explorar, o sentido subjetivo acima descrito. Trata-se dos aspectos motivadores da vinda dos primeiros exploradores, perpassando toda a trajetória sucedida em Ouro Preto até os dias atuais.

Sob um presente marcado por um passado manchado pela escravidão muitas famílias perpetuam a subserviência e o respeito desmedido pela tradição 
do Sobrenome. Há no imaginário popular uma linha divisória demarcando o espaço dos ricos e aquele permitido às classes populares. Impera também a ideia de invasão por forasteiros, nos quais subtraem as riquezas locais e as oportunidades de prosperidade.

Por conta disso, esse mal-estar passa de geração a geração sem ganhar nome ou sentido, mas são fortemente observadas na postura passiva e conformista dos moradores. Eis o motivo de se expressarem sempre que encontram oportunidade de dar vazão. Por levar em consideração tal manifestação, recorrente nos encontros com os usuários desse órgão público, este trabalho acolheu-a com cuidado e respeito.

Foi atendendo a estes anseios, que visitas técnicas em pontos turísticos e estratégicos da cidade foram incluídas na primeira fase do projeto. Buscou-se também possibilitar um maior acesso e conhecimento pelos participantes de possíveis campos de trabalho. Essa noção decorre do crescimento exponencial do turismo como uma das principais atividades econômicas em todo o mundo, gerando empregos e contribuindo para o desenvolvimento sustentável da economia.

Para ALVES (2016),

[...] Em geral, a atividade é vista e propagada nessas regiões como positiva, enfatizando-se a oferta de empregos e serviços que gera para os sujeitos e as regiões envolvidas, ou seja, privilegia-se nesse discurso o aspecto econômico da atividade, ou os benefícios financeiros por ela gerados. [...] No Brasil, em geral, a mão de obra feminina representa $82 \%$ dos empregos no núcleo do turismo (ALVES, 2016, p. 16-17).

Acresce-se o potencial do município de Ouro Preto, com títulos internacionais e reconhecimento mundial da sua história colonial, cujos casarios ainda se mantem preservados.

\section{CRAS - a Assistência Social Territorializada}

O Centro de Referência de Assistência Social, órgão público de intervenção descentralizada da política de Assistência Social - conhecido popularmente como a "Casa das Famílias" - é responsável pela organização e oferta dos serviços socioassistenciais da Proteção Social Básica do Sistema Único de Assistência Social (SUAS) nas áreas de vulnerabilidade e risco social dos municípios e Distrito Federal. Com este serviço visa-se, basicamente, conhecer 
de modo territorializado a incidência das situações de vulnerabilidades e riscos sociais, fortalecer os vínculos familiares e comunitários, por meio do desenvolvimento de potencialidades e ampliação do acesso aos direitos de cidadania e melhoria de sua qualidade de vida. (BRASIL, 2014, p.09).

A "Casa das Famílias" tem como princípios organizativos dois eixos estruturantes do SUAS: a matricialidade sociofamiliar, em que a família é reconhecida como o núcleo primário de afetividade, acolhida, convívio, sociabilidade, autonomia, sustentabilidade e referência no processo de desenvolvimento e reconhecimento da cidadania; e a territorialidade, na qual entende o território como o espaço da diversidade de interesses, disputas, conflitos, mas também de oportunidades, inovação, solidariedade, criatividade, valores dos indivíduos, grupos, cultura, experiências dos grupos, participação, inserção social, capacidades, habilidades, forças de resistência e existência, trajetórias, redes e parcerias. Portanto, o diagnóstico familiar também deve se ocupar da análise desses aspectos simbólicos que influenciarão as diversas ações desenvolvidas (MDS, 2012, p. 09).

Conforme define o Ministério do Desenvolvimento Social e Combate a Fome (2004):

A proteção social básica tem como objetivos prevenir situações de risco por meio do desenvolvimento de potencialidades e aquisições, e o fortalecimento de vínculos familiares e comunitários. Destina-se à população que vive em situação de vulnerabilidade social decorrente da pobreza, privação (ausência de renda, precário ou nulo acesso aos serviços públicos, dentre outros) e, ou, fragilização de vínculos afetivos - relacionais e de pertencimento social (discriminações etárias, étnicas, de gênero ou por deficiências, dentre outras). (MDS, 2004, s.p)

$\mathrm{Na}$ cidade de Ouro Preto há em funcionamento cinco unidades do CRAS, distribuídos estrategicamente em seu território, sendo duas unidades na sede, denominadas CRAS Alto da Cruz (região leste) e CRAS São Cristóvão (região oeste), (ver figura 1) e três em diferentes distritos, a saber: Antônio Pereira, Cachoeira do Campo e Santa Rita de Ouro Preto. Estas três últimas citadas, assumem a oferta de serviços, programas e projetos em Assistência Social nestas localidades e em subdistritos adjacentes.

O Centro do Alto da Cruz foi o primeiro a ser implantado no município, tendo 2006 como o ano de início de suas atividades. Atualmente está situado na Rua Nossa Senhora do Parto, $n^{\circ} 245$, Bairro Padre Faria e seu território 
de atuação compõe-se na atualidade de 15 bairros (vide figura 2), sendo eles: Alto da Cruz, Alto das Dores, Antônio Dias, Caminho da Fábrica, Catarina Mendes, Morro da Queimada, Morro Santana, Morro São João, Morro São Sebastião, Padre Faria, Perita, Piedade, Santa Cruz, Santa Efigênia e Taquaral.

Ao final de 2017, o CRAS Alto da Cruz totalizava 2387 cadastros de famílias que desde a sua fundação foram atendidos e/ou acompanhados pela equipe do Serviço de Proteção Social Básica. E, somando-se a este dado, vale esclarecer a existência de 51 famílias assistidas pelo PAIF, atualmente.

Fıcura 1: Mapa com a distribuição de bairros na cidade de Ouro Preto

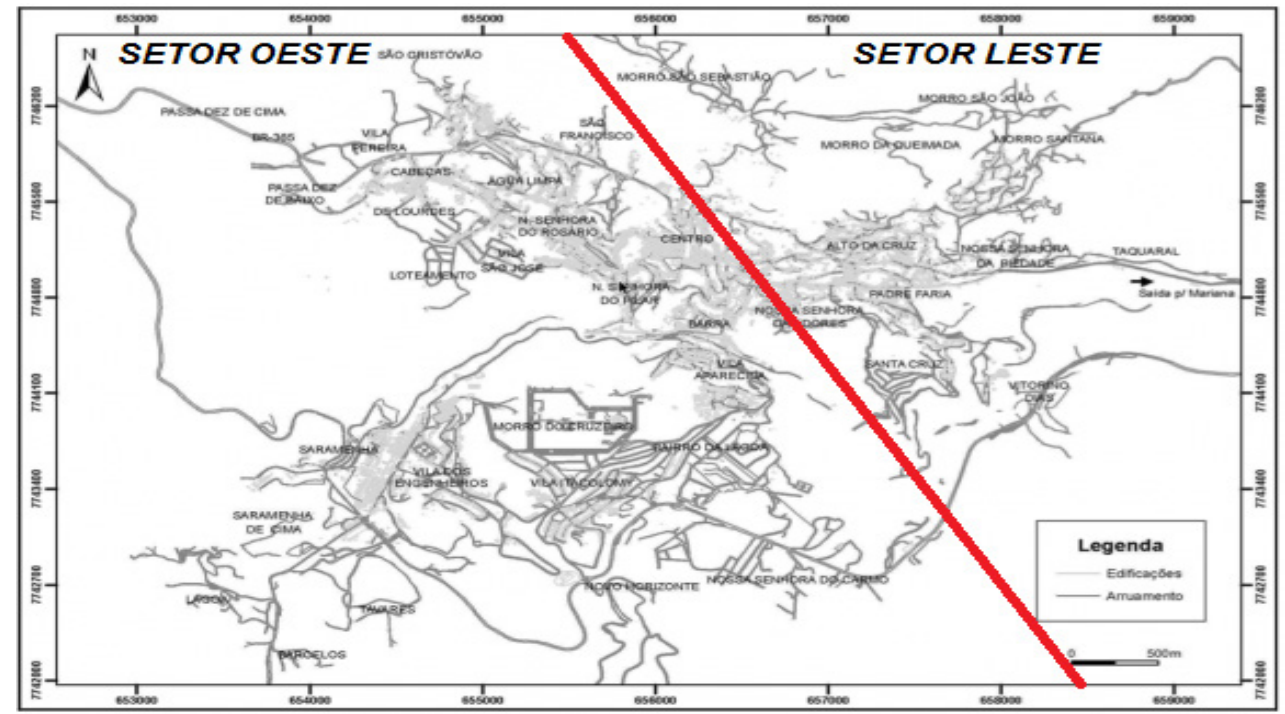

FONTE: CASTRO, 2006.

Observa-se na Figura 1 (mapa adaptado) que o CRAS Alto da Cruz compreende, por intermédio de uma linha imaginária, os bairros da zona leste na sede da cidade, cuja área concentra em altos índices as mais recorrentes Questões Sociais no município. Essa realidade justifica a escolha do público atendido por este Centro de Referência na interlocução com a Universidade, nessa referida atividade de extensão. 
Ficura 2: Cráfico de atendimentos por bairro

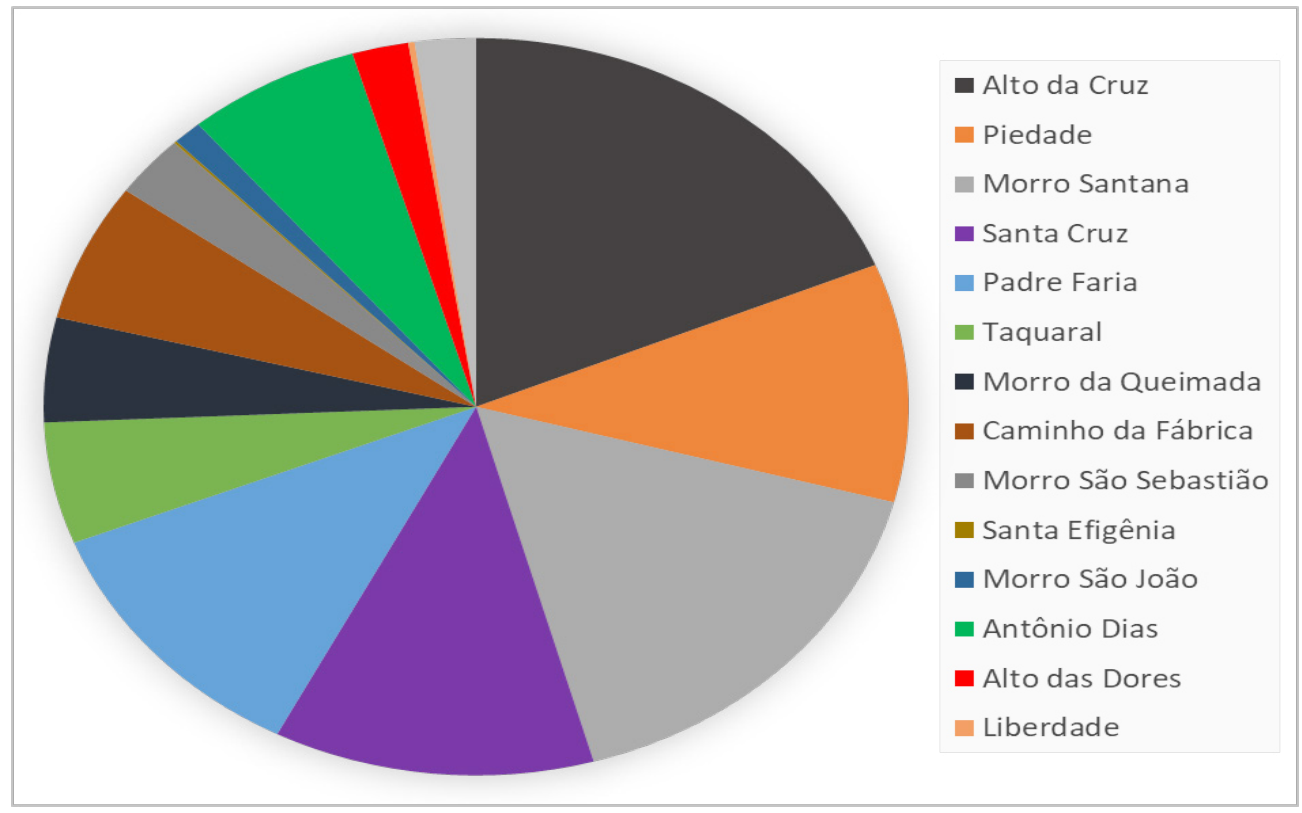

FONTE: ARQUIVO CRAS ALTO DA CRUZ, 2017.

Com base nos dados coletados entre os meses de março a dezembro de 2017, nos registros efetuados pela recepção do serviço do CRAS, observa-se que os bairros Alto da Cruz, Piedade, Morro Santana, Santa Cruz e Padre Faria são aqueles com maior número de atendimentos. E, em uma segunda análise são também os bairros nos quais compreendem o maior número de famílias acompanhadas pelo PAIF.

\section{O Perfil das Famílias}

Conhecer o público-alvo é indispensável para o desenvolvimento de atividades, uma vez que estas contemplam finalidades e extrapolam a atividade em si. Afinal, apenas compreendendo bem o perfil dos participantes será possível estabelecer uma comunicação eficiente e desenvolver ações atinentes às suas reais necessidades. Mediante a análise dos 51 cadastros familiares atendidos pelo PAIF foi possível construir um perfil o qual será exposto a seguir.

Observou-se de antemão o fato destas famílias serem majoritariamente chefiadas por mulheres (92\%) com idade entre 30 a 49 anos. O gráfico abaixo ilustra essa configuração etária. 
Ficura 3: Gráfico média da idade dos componentes familiares

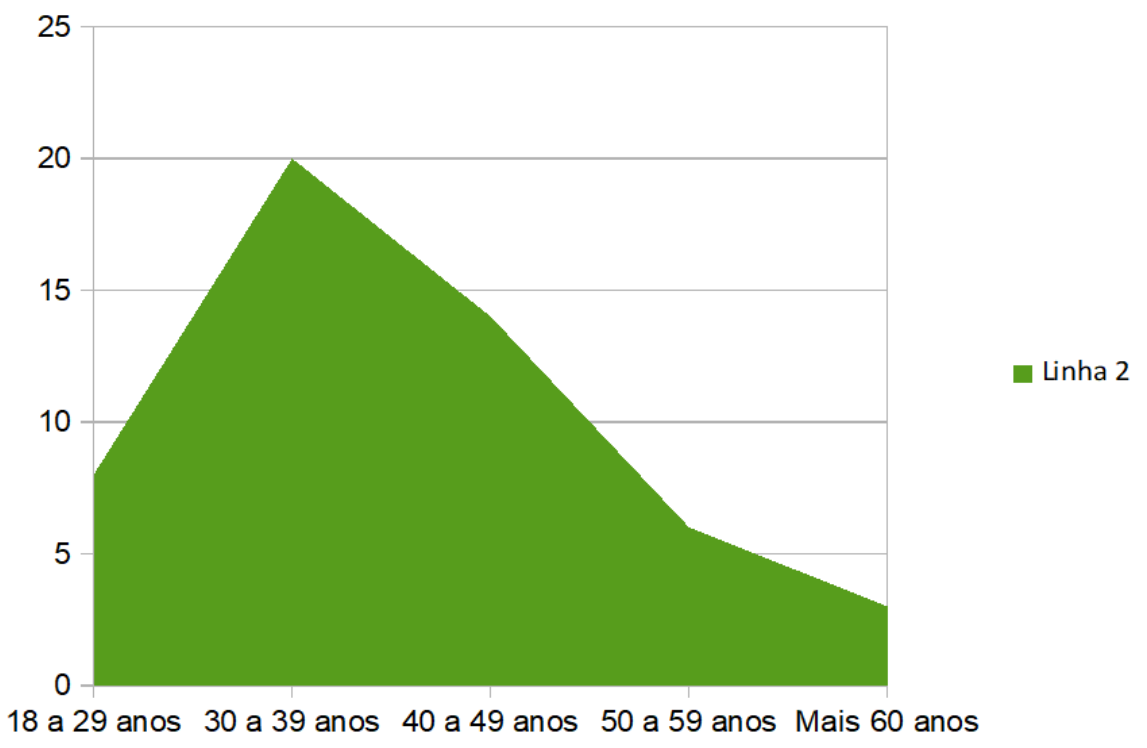

FONTE: ARQUIVO CRAS ALTO DA CRUZ, 2017

Quanto a composição, estas famílias são caracterizadas em sua maioria (72\%) pela presença de 03 até 06 membros, como se pode observar no gráfico a seguir.

FICURA 4: Cráfico da composição familiar

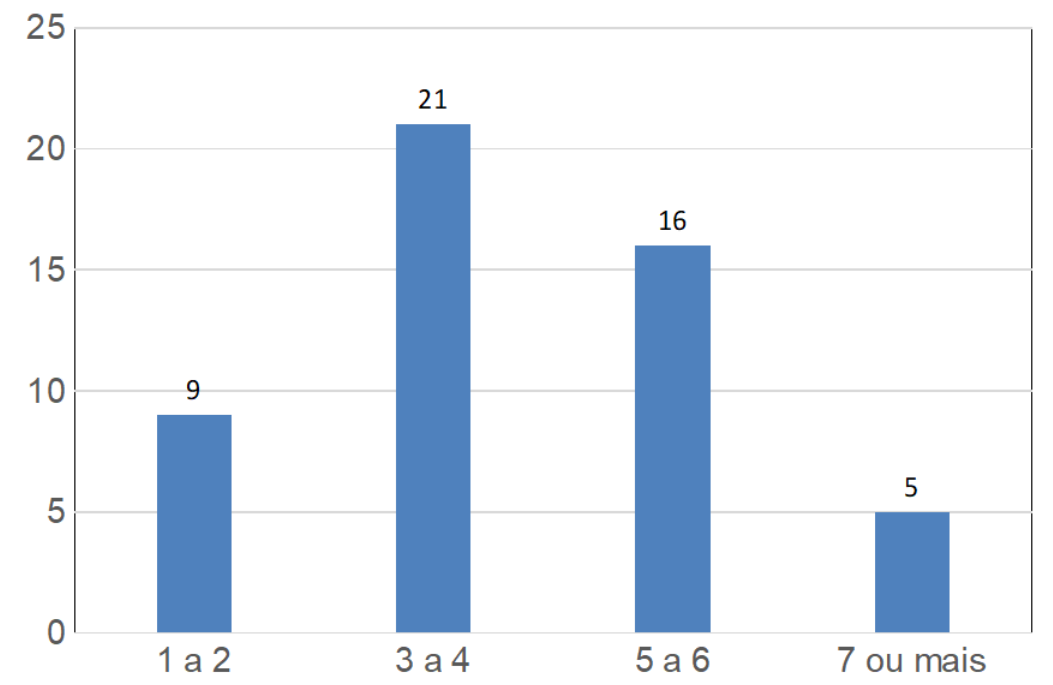

Fonte: ARQUIVO CRAS ALTO dA CRUZ, 2017 
Didaticamente podemos separar o universo de famílias analisadas em população economicamente ativa (78\%) e, de outro lado, população excluída do mercado de trabalho (22\%). Assim, tem-se a seguinte configuração:

FIcura 5: Tabela de parcela economicamente ativa

\begin{tabular}{|c|c|}
\hline SitUAÇÃo & RESPONSÁVEL FAMILIAR \\
\hline MERCADO INFORMAL DE TRABALHO & 21 \\
DESEMPREGADOS & 12 \\
\hline MERCADO FORMAL DE TRABALHO & 07 \\
SUBTOTAL & 40 \\
\hline
\end{tabular}

FONTE: ARQUIVO CRAS ALTO DA CRUZ, 2017. ${ }^{5}$

Através desta tabela, observa-se a forte exclusão das famílias acompanhadas pelo PAIF do mercado formal de trabalho. A parcela economicamente ativa, isto é, que possui idade produtiva representa 40 famílias do total, porém observa-se que apenas $17 \%$ dos indivíduos possuem suas Carteiras de Trabalho assinadas.

O mercado informal, caracterizado pela atividade autônoma, representa cerca de $52 \%$ da população em idade produtiva. Estes responsáveis familiares relataram não recolher contribuição junto ao Instituto Nacional de Seguro Social - INSS. Durante o acompanhamento socioassistencial, foram frequentes as queixas com relação as dificuldades desta inserção no mercado formal de trabalho, desde questões familiares como filhos menores dependentes de cuidados (faltam vagas em creches públicas para acolhê-los) e a falta de capacitação técnica para as vagas de emprego.

Cabe destaque ainda com relação a Figura 5 que 30\% da parcela apta ao mercado de trabalho possuem renda zero, isto é, estão em situação de extrema pobreza, sem qualquer fonte de renda e se quer conseguem realizar atividades esporádicas, os populares "bicos". Esta informação foi primordial para direcionar a busca ativa dos participantes, focando nas áreas de maior vulnerabilidade econômica.

5 Neste recorte são considerados responsáveis familiares desempregados e sem qualquer atividade no mercado informal. 
FicuRa 6: Tabela parcela economicamente inativa

\begin{tabular}{|c|c|} 
SUBTOTAL & $\mathbf{1 1}$ \\
\hline APOSENTADORIA POR IDADE OU INVALIDEZ & 06 \\
\hline BENEFí́CIO ASSISTENCIAL (BPC) & 05 \\
\hline
\end{tabular}

FontE: ARQUiVo CRAS ALTO dA CRUZ, 2017.

Esta parcela das famílias em análise socioeconômica representa os responsáveis familiares inativos por serem idosos ou deficientes. São aposentados 55\% deles e, paralelamente estão recebendo o Benefício de Prestação Continuada ${ }^{6}$ o conjunto de $45 \%$. Averigou-se que cada família recebe um salário mínimo, cujo valor vigente em 2018 é de $\mathrm{R} \$ 954,00$ (novecentos e cinquenta e quatro reais).

Ficura 7: Gráfico da renda per capita

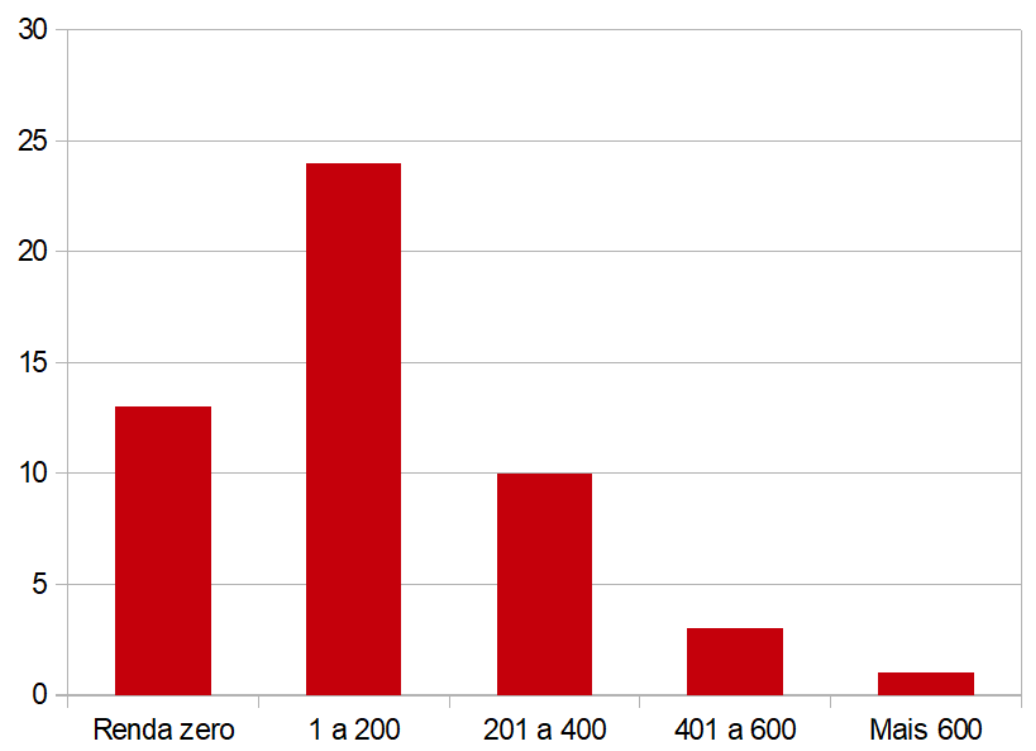

FONTE: ARQUIVO CRAS ALTO DA CRUZ, 2017.

A renda per capita, por sua vez, ao ser analisada revelou um predomínio de famílias com até $\mathrm{R} \$ 200,00$ (duzentos reais) - aproximadamente 70\% do universo.

6 O Benefício de Prestação Continuada é a garantia de um salário-mínimo mensal à pessoa com deficiência e ao idoso com 65 (sessenta e cinco) anos ou mais comprovando não possuir meios de prover a própria manutenção nem de tê-la provida por sua família, conforme Art. 20 da Lei no 8.742, de 7 de dezembro de 1993, que dispõe sobre a Lei Orgânica de Assistência Social - LOAS. 
Mediante a situação de baixa renda apresentada pelas famílias, configuram-se como potenciais beneficiários do repasse do Programa Bolsa Família, sendo que das 51 famílias analisadas 30 delas (59\%) recebem este benefício do Governo Federal e outras estão com Cadastro Único ${ }^{7}$ ativo e válido ou em análise, aguardando posterior concessão. Vale observar a média dos valores recebidos por família, o montante de $\mathrm{R} \$ 239,00$ (duzentos e trinta e nove reais).

O Programa Bolsa Família contempla indivíduos e famílias em situação de vulnerabilidade econômica, através de repasses financeiros mensais, cujos valores variam conforme a renda per capita declarada e composição familiar, basicamente. Há variáveis etárias que determinam os valores, não nos cabendo deter por ora.

Um dado a ser considerado ainda na construção do perfil destas famílias diz respeito aos bairros onde residem. A área de abrangência desta unidade, como supramencionado, é de 15 bairros e, temos em questão famílias residindo em 12 deste universo. Para melhor visualização podemos utilizar a figura abaixo:

FIcuRA 8: Bairros de residência

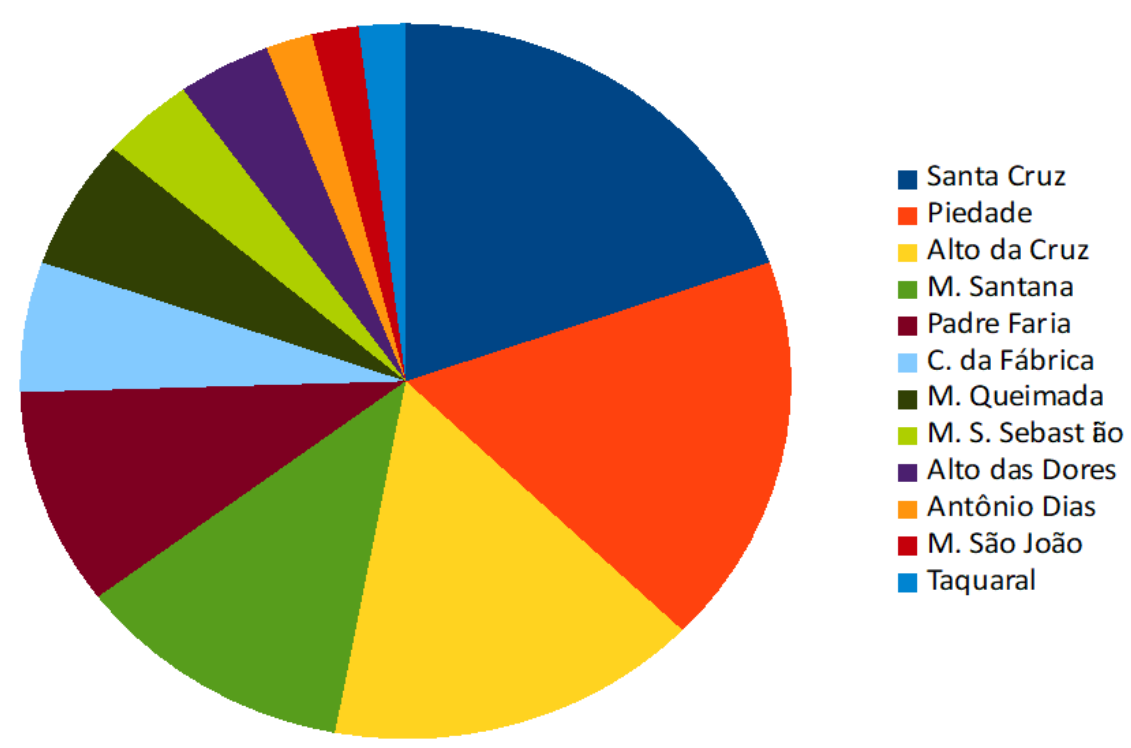

FONTE: ARQUIVO CRAS ALTO DA CRUZ, 2017.

7 O Cadastro Único para Programas Sociais - conhecido como CadÚnico é instrumento de identificação e caracterização socioeconômica das famílias brasileiras de baixa renda a ser obrigatoriamente utilizado para seleção de beneficiários e integração de programas sociais do Governo Federal voltados ao atendimento desse público (Decreto $n^{\circ} 6.135$, de 26 de junho de 2007). 
Esta informação, claramente visualizada no gráfico anterior, revela a distribuição do trabalho com famílias por este órgão municipal, bem como a incidência de vulnerabilidades de forma dispersa em toda sua área de abrangência. Nestes bairros, os tipos de moradias são em grande maioria próprios (27\%), herdados ou adquiridos. Há também moradias em ocupação irregular, na qual a posse não é legalizada/autorizada (2\%).

FIGURA 9: Tipos moradia

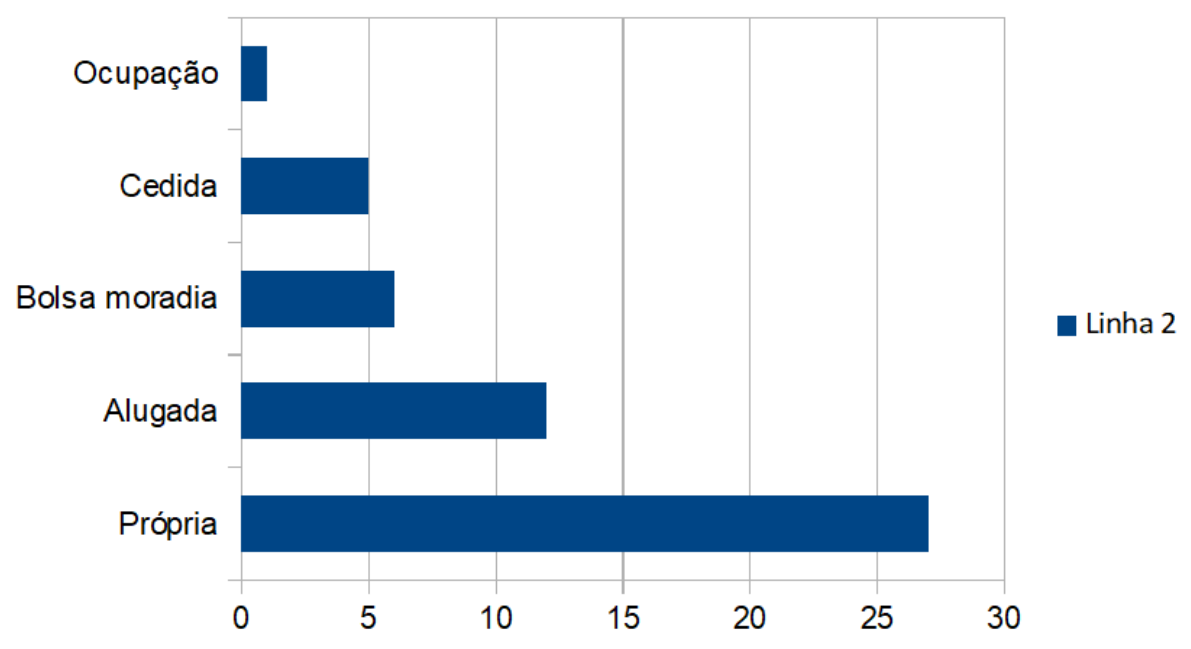

FONTE: ARQUIVO CRAS ALto DA CRUZ, 2017

O Bolsa Moradia - situação frequente em 12\% da amostra analisada - é um benefício municipal destinado às famílias que tiveram suas casas interditadas por situações adversas como destruição total ou parcial motivada por incêndio, estrutura danificada, precariedade na construção ou instabilidade do solo/terreno, entre outras situações climáticas. Trata-se de um Programa Habitacional Municipal regido pela Lei Municipal no 1.076, de 26 de dezembro de 2017.

Em suma, temos o seguinte perfil construído a partir dos dados levantados: famílias chefiadas majoritariamente por mulheres, na faixa etária dos 30 aos 49 anos, residentes em casa própria, em situação de baixa renda (desempregadas) e beneficiárias do Programa Federal do Bolsa Família. Dentro desta ótica tentou-se dar maior emponderando as mulheres chefes dessas famílias, nas quais se encontram contraditoriamente em idade produtiva, porém excluídas do mercado formal de trabalho.

Com base nos dados apresentados ao longo desse texto percebe-se a necessidade de redimensionar a lógica do trabalho com famílias na perspectiva dos 
direitos - caminho para a concretização da cidadania, via políticas públicas de responsabilidade estatal. Por conseguinte, as ações atentaram para o reconhecimento das famílias como sujeitos de sua transformação e atores do seu processo de desenvolvimento.

\section{O Projeto}

Este projeto buscou parcerias com entidades locais, comércio, indústrias e demais instituições, contribuindo para alavancar sua proposta. Estabeleceu Parcerias Público Privadas (PPP) com empresas atuantes no município, para que as demandas geradas fossem viabilizadas, garantindo não só maior conscientização de todos os setores, como também a capilaridade de seus objetivos e sua repercussão.

Há de ressaltar a participação ativa e multidisciplinar da equipe composta por Psicólogos, Assistentes Sociais, Turismólogos e Professores Universitários da área do Turismo, além de estagiários de Serviço Social e Turismo, no qual dois destes estiveram na condição de Bolsista da Pró-reitoria de Extensão (Proex) e também estudantes de graduação em Turismo na condição de voluntários.

Os profissionais totalizaram ao final de 2017 aproximadamente 20 colaboradores e juntamente com o público-alvo realizaram atividades variadas, perpassando ações como cursos de capacitação profissional, reuniões, oficinas, palestras, visitas técnicas e dinâmicas grupais.

Essa interação foi contributo não apenas ao público, no qual se direcionou as ações, mas também aos discentes graduandos em Turismo e Serviço Social, também acompanhados em todo o processo. Debates críticos, analíticos, multifacetados e de conjuntura foram propiciados com esta interlocução, A troca de saberes, de informações técnicas, sobre o funcionamento dos diferentes órgãos e instituições púbicas e privadas articuladas geraram uma carga de conhecimento sobremaneira para futuras atuações profissionais.

\section{Como lembra GOMES (2016):}

A fragmentação do saber atendeu a expectativa do modo capitalista até certo ponto. As relações sociais fundamentadas nas relações de produção, produziram sujeitos cada vez mais especializados, contudo, apresentou complexidades que esses profissionais especializados não conseguem explicar e/ou responder (p.03). 
Por isso, reforça-se o valor e a necessidade de práticas interdisciplinares nos diferentes espaços de atuação profissional.

Vale mencionar ainda, que a divulgação das atividades ocorreu continuadamente através dos meios oficiais de comunicação, como site da Prefeitura Municipal, Rádio UFOP, panfletos e reuniões comunitárias. O público-alvo, por sua vez, foi convidado por meio de atendimentos espontâneos, visitas domiciliares, cartas e telefonemas. Antecedendo os passeios guiados ocorreram ao menos uma reunião entre os atores envolvidos para realização de acordos, esclarecimentos, escolha de datas e locais a serem visitados, além de outras disposições necessárias.

Em nove meses, realizou-se encontros semanais entre os participantes, encontros estes realizados em múltiplos espaços. A definição dos locais se deu através de planejamento da equipe técnica, o qual atentou, dentre outros aspectos, para datas festivas e por contribuição democrática e coletiva dos demais atores. A participação coletiva ocorreu de maneira direta e indireta, verbal ou escrita.

\section{Das Atividades Desenvolvidas}

No âmbito da capacitação profissional, realizaram-se palestras com temas selecionados pela equipe coordenadora ou por indicação dos usuários, a saber: Inclusão Produtiva; Programa Bolsa Família; Serviços e Benefícios do CRAS; Empreendedorismo - MEI (Microempreendedor individual); Autonomia; Cidadania e participação; Recursos turísticos em Ouro Preto e Emponderamento feminino.

Somam-se ainda, cursos profissionalizantes na área de Culinária e Camareira destinados aos participantes interessados, culminando com a participação da Carreta Escola do Serviço Nacional de Aprendizagem Comercial (SENAC), no qual por uma semana puderam de forma prática ensinar tais habilidades profissionais.

A realização de oficinas surgiu como demanda de participantes interessados nos temas artesanato, culinária e atividades manuais, sendo realizados com estes: oficinas de Quitandas natalinas (panetones e rabanada); Guirlandas decorativas; Móveis e objetos de papelão e Artes Plásticas (acabamentos e precificação).

Atividades manuais foram recorrentemente demandadas pelos usuários, e tais cursos e oficinas acima citados ocorreram com o intuito de prepará-los 
para o mercado formal de trabalho, ou ainda, serem uma fonte alternativa de renda, através da venda dos produtos confeccionados, sejam eles artesanais ou de panificação.

Dentre as visitas técnicas, a aliança firmada com o IPHAN e Secretaria de Turismo da Prefeitura Municipal de Ouro Preto, permitiu fornecer guias turísticos e profissionais capacitados para orientar visitas técnicas na Feira Nacional de Artesanato em Belo Horizonte; no Museu Casa Guignard, no Museu Casa de Gonzaga, no Arquivo Público Municipal, além do Roteiro Sentidos Urbanos do Instituto do Patrimônio Histórico e Artístico Nacional (IPHAN).

Todas as atividades educativas e preparatórias foram certificadas em um evento solene de encerramento do projeto.

Avaliações

Foram aplicados 36 questionários ao longo do projeto sobre algumas atividades e foi sugerido a pontuação em aspectos como: didática de ensino; domínio de conteúdo; administração do tempo de aula; relacionamento com a turma; e condições das atividades práticas. Cada participante, presente na data de aplicação deste instrumento, pode empregar notas de 1 a 5, sendo 1 péssimo e 5 excelente. Foi possível observar uma grande satisfação tendo 301 votos classificados como excelente e apenas 3 votos classificados como ruim.

Essa estratificação segue demonstrada abaixo.

FIGURA 10: Tabela pontuação

\begin{tabular}{|c|c|}
\hline AVALIAÇÃo & Votos \\
\hline PÉSSIMO & 0 \\
\hline RUIM & 3 \\
\hline REGULAR & 24 \\
BOM & 189 \\
ÓTIMO & 301 \\
\hline
\end{tabular}

FONTE: ARQUIVO CRAS ALTO DA CRUZ, 2017. 
Fıcura 11: Cráfico satisfação atividades da primeira fase

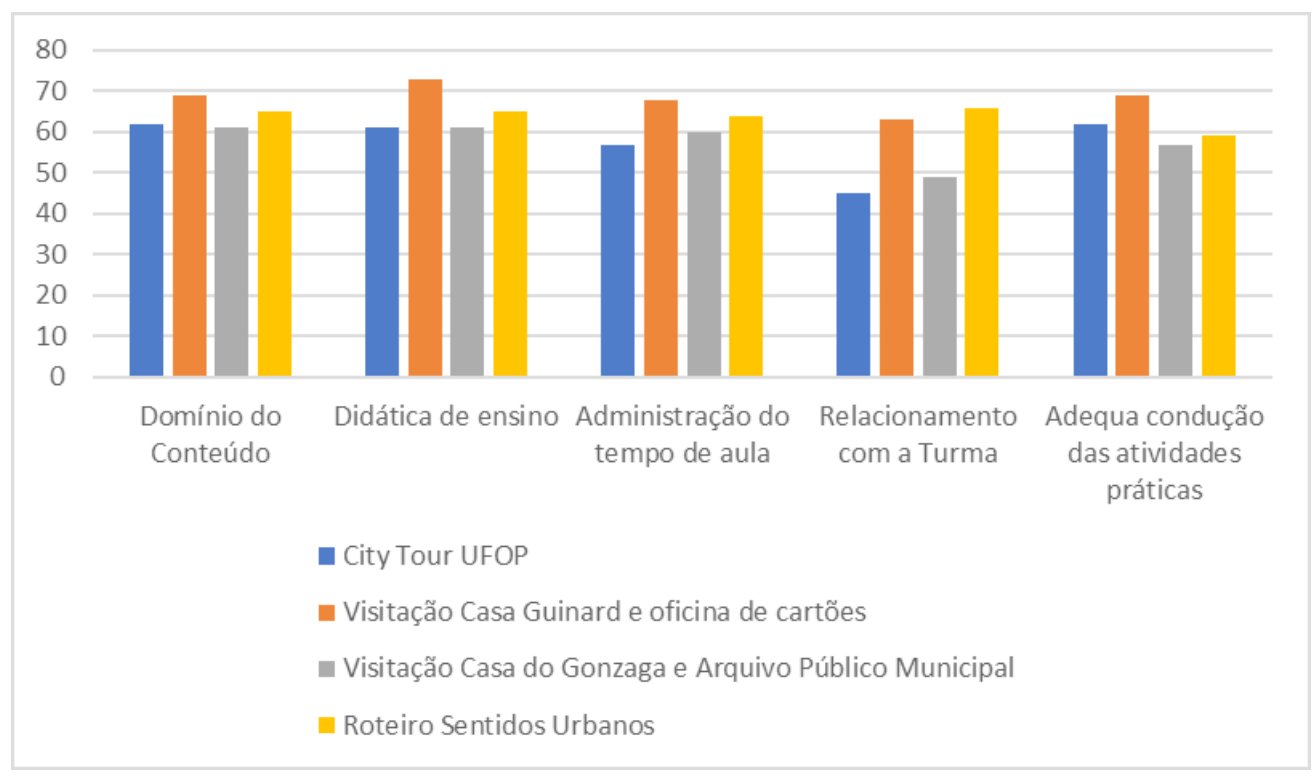

FONTE: ARQUIVO CRAS ALTO DA CRUZ, 2017.

A divisão entre primeira e segunda fases correspondem, respectivamente, o primeiro e segundo semestre de 2017. Dentre o primeiro conjunto de atividades avaliadas, a que obteve maior índice de votos foi a Visitação na Casa Guinard e a oficina de cartões realizada neste local. Por último, nos critérios avaliativos encontraram-se as atividades de Visitação na Casa de Gonzaga e o City Tour feito na UFOP.

FICURA 12: Cráfico satisfação atividades da segunda fase

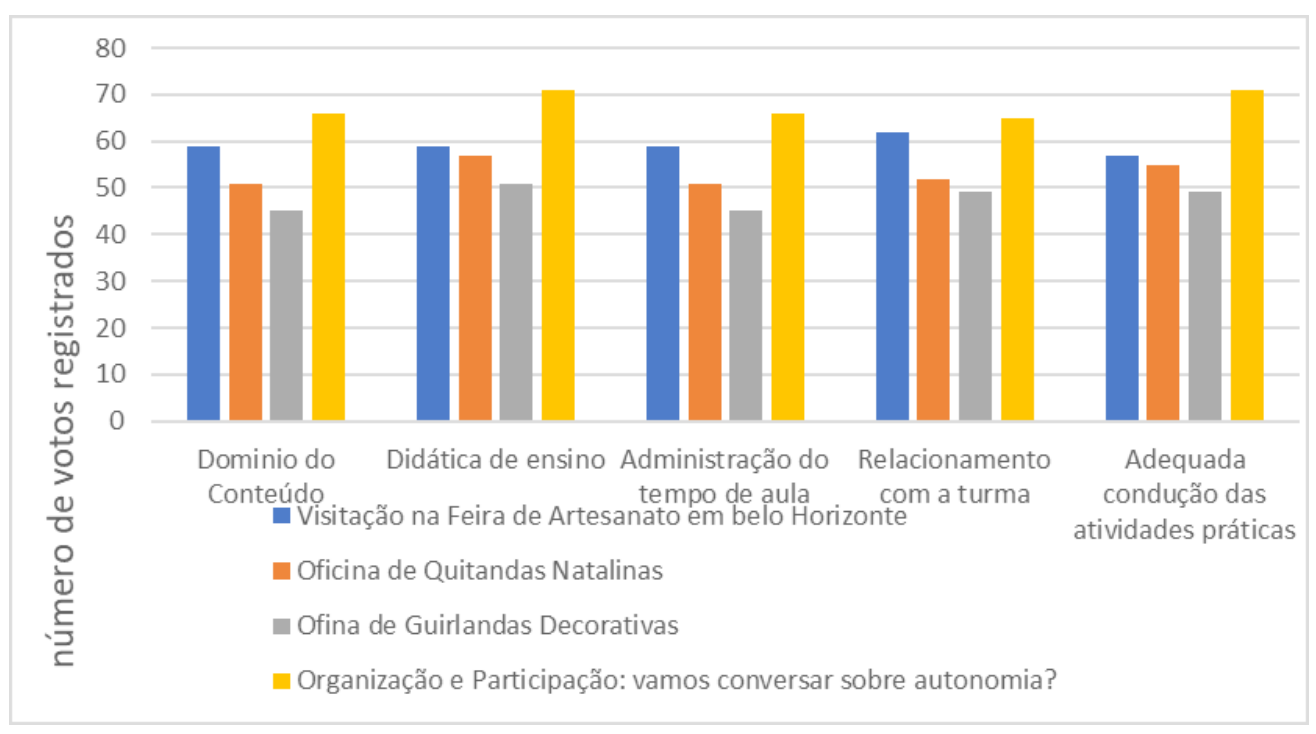

FONTE: ARQUIVO CRAS ALTO dA CRUZ, 2017. 
De acordo com os dados coletado no segundo questionário foi possível constatar uma satisfação principalmente na atividade de "Organização e Participação: vamos conversar sobre autonomia?”. E, contrariamente com menor índice de aprovação por parte dos participantes temos a Oficina de Guirlandas natalinas.

Tendo em vista a alta incidência de desemprego dentre os participantes, esse resultado sugere que uma atividade lançou luz sobre a angústia vivenciada por essa situação, permitindo sua verbalização e reflexão trouxe uma satisfação ao grupo.

Pode-se avaliar, que as três atividades mais bem avaliadas são de naturezas diferentes, quais sejam: visita técnica (Museu Casa Guinard); oficina (Confecção de cartões); palestra ("Organização e Participação: vamos conversar sobre autonomia?"). Revelam com isso, que a boa condução da atividade envolvendo infraestrutura adequada, suporte profissional e boa oferta de materiais foram determinantes positivamente para os participantes. E, não necessariamente o tipo de atividade em si determinou a nota conferida pelos usuários. Por outro lado, os eventos avaliados negativamente se deram em função de frágil organização, escassez de insumos ou necessidade de improvisos.

Muitos ajustes foram sugeridos em avaliações formais (questionários previamente estruturados e aplicados semestralmente) e informais (diálogo emergido em um ambiente democrático de vivências). Apontando desde a alterações de horários, cronograma e frequência dos encontros. Palestras também foram incluídas em função de temas sugeridos, como: Cuidados com Idosos; Estatuto da Criança e Adolescente (ECA); Conflitos Intergeracionais, Gênero, Raça/Etnia; BPC (Benefício de Prestação Continuada) e Abuso e Violência na Infância e Adolescência.

As avaliações ocorridas em cada fase do projeto se deram, portanto, para levantamento de expectativas e aprimoramento de ações, compilação de resultados, permitindo os ajustes necessários.

\section{Considerações Finais}

Importa afirmar que o relato desta experiência não se esgota neste artigo, tão pouco as informações socioeconômicas aqui apontadas foram analisadas exaustivamente, visto a dinamicidade e complexidade da vida social. Estudos e reflexões futuras se fazem necessárias e complementares. Para o segundo 
semestre de 2018, no âmbito da parceria relatada neste artigo, pretende-se através de pesquisa quali-quantitativa mensurar os novos acessos ao mercado de trabalho, assim como a formalização e consolidação dos empreendimentos nascidos nesta experiência.

ALVES (2016) compartilha desta perspectiva e alerta:

Ainda que timidamente, planos para novas pesquisas, políticas e estratégias na área, abordando a temática gênero e trabalho em turismo, começaram a se desenvolver. No entanto, ações efetivas, tanto no âmbito público quanto no privado, em todos os níveis, são imprescindíveis à incorporação de condições de igualdade entre homens e mulheres, de modo a promover a elevação da qualidade do emprego das mulheres e a superação de todas as formas de discriminação (p. 24).

É inegável que desafiar as atitudes com relação ao trabalho da mulher exige uma abordagem multifacetada. Sabemos pois, a necessidade dos governos em adotar medidas legislativas, administrativas e financeiras para criar um ambiente sólido e favorável ao empreendedorismo feminino e à participação da mulher no mercado de trabalho, como a oferta de serviços de creche seguros, acessíveis e de qualidade. Isso permite a elas maior mobilidade, aumento do controle sobre seus recursos e fortalece a consciência política. Dar maior poder às mulheres por meio de outros tipos de investimento - a exemplo de capacitações e acesso a novas tecnologias - pode ter efeitos positivos sobre o crescimento econômico e a redução da pobreza.

As demandas são variadas e desafiantes, reforçando a validade do projeto de "Valorização e Capacitação Técnica de Jovens e Mulheres para o Turismo", assim como a imposição de reformulações e aprimoramentos para a sua continuidade em 2018. Acredita-se que embora careça de mais aprimoramento, essa experiência foi inovadora e gerou impactos positivos na comunidade envolvida. Propiciando crescimento a todos os participantes, característica marcantemente revelada no protagonismo de cada membro nos encontros e nas dinâmicas com forte integração.

Ao longo de todos os eventos os participantes verbalizaram o efeito positivo da aproximação com o espaço da Universidade, até então desconhecido pela maioria. Sinalizaram, principalmente nas rodas de conversa, as poucas oportunidades tidas durante sua vida de adentrar os principais pontos turísticos da cidade, resistência rompida pelas oportunidades do projeto. 
Indiretamente, por meio de diálogos e reflexões, provocou o pensar crítico no grupo sobre o motivo que subjaz as dificuldades de desenvolverem o sentimento de pertença no seu espaço de vivência e convivência. Todavia, é preciso reconhecer a incipiência dessa iniciativa. Ainda não se apresenta fortemente estruturada a ponto de provocar mudanças no cenário de exclusão social, diariamente vivenciadas no atendimento familiar executado no CRAS. Tampouco foi capaz de romper com o preconceito presente no espaço universitário, haja vista algumas situações discriminatórias vivenciadas por alguns dos participantes durante atividades desenvolvidas no interior da UFOP.

A articulação entre as diferentes entidades e seus representantes ampliaram a margem de atuação e alcance das ações. Neste caso, em especial, houve a aproximação do saber científico com as mazelas sociais, possível apenas quando o saber teórico de fato enxerga e escuta a população. Extrapolar o trabalho rotineiro e, por vezes, burocrático, se faz necessário. É preciso romper com as amarras do serviço público quando este se dá extremamente institucionalizado em seu restrito espaço físico, buscando com inventividade e criatividade alternativas para a escassez de recursos humanos e materiais e a carência de investimentos.

A atuação profissional no âmbito da Assistência Social, atingida por frequentes cortes orçamentários na pasta, acarretam em forte defasagem na oferta de recursos humanos, meios e condições de trabalho. Não são desconhecidos os ataques sofridos também pelas Universidades públicas em tempos de neoliberalismo. São (contra) reformas atentando sobremaneira todos os segmentos da sociedade, os trabalhadores em todas suas dimensões e colocando desafios e impasses à concretização de trabalhos sistemáticos e continuados. Temos, por conseguinte, grandes prejuízos à qualidade nas prestações de serviços sociais e à formação nos âmbitos da graduação e pós-graduação. Prevê-se, com isso, enormes desafios, mas não sendo capazes de minar as grandes possibilidades propiciadas pelo senso crítico e mobilização popular. Essa questão fica como reflexão e não exige, tampouco deseja, uma resposta apressada.

Finalizando, cabe ressaltar a necessária articulação entre o saber científico e as demandas sociais na afirmação e construção de identidades, com vistas a auxiliar o conhecimento e a percepção da potencialidade local e o atendimento às demandas sinalizadas pela Secretaria Municipal de Desenvolvimento Social, Habitação e Cidadania de Ouro Preto. Assim, o projeto apresenta diversas opções à capilaridade da atividade turística, podendo beneficiar não somente as entidades com ela envolvidas, mas toda a comunidade e município. $\mathrm{O}$ viés 
social apresentado, permite inserir aqueles atores em situação de vulnerabilidade social, capacitando-os e por consequência promovendo a geração de emprego e renda, objetivando reverter em benefícios de inclusão e diminuição de estado de carência.

Finalizando, espera-se que este artigo possa promover reflexões sobre a necessária interlocução entre a Assistência Social e a Universidade, visto o relevante potencial desta possível aliança.

\section{REFERÊNCIAS}

ALVES, K. dos S. Turismo, trabalho e gênero: uma abordagem interdisciplinar. Ouro Preto: UFOP/Departamento de Turismo, 2016.

ANTUNES, R. L. Adeus ao trabalho? Ensaio sobre as metamorfoses e a centralidade do mundo do trabalho. II. cd. São Paulo: Cortez, 2006.

CRAS ALTO DA CRUZ, Arquivo interno. Secretaria Municipal de Desenvolvimento Social, Habitação e Cidadania. Ouro Preto, 2017.

BATINNI, O. SUAS: Sistema Único de Assistência Social em debate. São Paulo: Veras Editora, 2007.

BRASIL, Cadastro Único para Programas Sociais do Governo Federal. Brasília: MDS, 2007.

Constituição da República Federativa do Brasil. Brasília, 1988.

Curso de atualização em vigilância socioassistencial do SUAS. Ministério do Desenvolvimento Social e Agrário. Brasília, 2016.

Lei no ${ }^{\circ} .742$, de 7 de dezembro de 1993. Dispõe sobre a Lei Orgânica de Assistência Social - LOAS. Brasília, 1993.

Orientações Técnicas sobre o PAIF. O Serviço de Proteção e Atendimento Integral à Família - PAIF. 1 ed. Vol. 1. Brasília: MDS, 2012.

Resolução no 145, de 15 de outubro de 2004. Aprova a Política Nacional de Assistência Social - PNAS. Brasília: MDS, 2004.

Resolução CNAS no 109, de 11 de novembro de 2009. Aprova a Tipificação Nacional de Serviços Socioassistenciais. Brasília: CNAS, 2014. Reimpressão.

Trabalho Social com Famílias. Brasília: SNAS, 2014.

CASTRO, J. M. Pluviosidade e movimentos de massa nas encostas de Ouro Preto. Dissertação (Mestrado) - Universidade Federal de Ouro Preto. Escola de Minas. Departamento de Engenharia Civil. Ouro Preto: UFOP, 2006. 
FRIZZO, G. F. E., MARIN, E. C. \& SCHELLIN, F. O. A extensão universitária como elemento estruturante da Universidade pública no Brasil. Revista Currículo sem Fronteiras. V. 16, L. 3, p. 623-646. Set/dez. 2016

GOMES, N. A. Serviço Social e interdisciplinariedade: confluências e desafios. $4^{\circ}$ Simpósio Mineiro de Assistentes Sociais. Belo Horizonte, 2016

IAMAMOTO, M. V. O Serviço Social na contemporaneidade: trabalho e formação profissional. São Paulo: Cortez, 1998.

LESTINGE, S. R. Olhares de educadores ambientais para estudo do meio e pertencimento. Dissertação (Doutorado em Recursos Florestais). Escola Superior de Agricultura Luiz de Queiroz: Universidade de São Paulo, 2004.

SITES

Blog Patrimônios históricos do Brasil. Disponível em: http://patrimonioshistoricosbr. blogspot.com.br/2011/04/cidade-historica-de-ouro-preto-minas.html. Acesso em: 10 de fevereiro de 2018, às 15:01 horas.

IBGE - Instituto Brasileiro de Geografia e Estatística. Disponível em: https://cidades. ibge.gov.br/brasil/mg/ouro-preto/panorama. Acesso em: 11 de fevereiro de 2018, às 15:34 horas.

SUAS - Sistema Único de Assistência Social. Disponível em: http://www.mds.gov.br. Acesso em: 22 de fevereiro de 2018, às 19:04 horas.

UFOP - Universidade Federal de Ouro Preto. Disponível em: http://ufop.br/historia-da-ufop. Acesso em: 02 de fevereiro de 2018, às 09:22 horas. 